\title{
miR-212-5p suppresses lipid accumulation by targeting FAS and SCD1
}

\section{Yajie Guo, Junjie Yu, Chunxia Wang, Kai Li, Bin Liu, Ying Du, Fei Xiao, Shanghai Chen and Feifan Guo}

Key Laboratory of Nutrition and Metabolism, Institute for Nutritional Sciences, Shanghai Institutes for Biological Sciences, Chinese Academy of Sciences, University of Chinese Academy of Sciences, Shanghai, People's Republic of China
Correspondence should be addressed to F Guo Email

ffguo@sibs.ac.cn

\begin{abstract}
MicroRNAs, a class of small noncoding RNAs, are implicated in controlling a variety of biological processes. We have shown that leucine deprivation suppresses lipogenesis by inhibiting fatty acid synthase (FAS) expression in the liver previously; the aim of our current study is to investigate which kind of microRNA is involved in the regulation of FAS expression in response to leucine deprivation. Here, we indicated that microRNA212-5p specifically binds to mouse FAS $3^{\prime}$ UTR and inhibits its activity. Leucine deficiency significantly increased the mRNA levels of miR-212-5p in the livers of mice. Further studies proved that miR-212-5p also directly binds to the $3^{\prime}$ UTR of stearoyl-CoA desaturase-1 (SCD1) to inhibit its activity. Overexpression of miR-212-5p decreases the protein levels of FAS and SCD1 in vitro and in vivo, and silencing of miR-212-5p has the opposite effects in mouse primary hepatocytes. Moreover, overexpression of miR-212-5p significantly decreases triglyceride (TG) accumulation in primary hepatocytes and in the livers of mice injected with adenovirus-mediated overexpressing of miR-212-5p (Ad-miR-212). Interestingly, inhibition of miR-212-5p reverses the suppressive effects of leucine deficiency on FAS and SCD1 expression, as well as TG accumulation in mouse primary hepatocytes. Finally, we demonstrate that leucine deficiency induces the expression of miR-212-5p in a GCN2/ATF4-dependent manner. Taken together, our results demonstrate a novel function of hepatic miR-212-5p in the regulation of lipid metabolism which represents a potential therapeutic target for the treatment of non-alcohol fatty liver diseases (NAFLD).
\end{abstract}

\author{
Key Words \\ - miR-212-5p \\ - FAS \\ - SCD1 \\ - lipid accumulation \\ - NAFLD
}

Journal of Molecular Endocrinology (2017) 59, 205-217

\section{Introduction}

Non-alcoholic fatty liver disease (NAFLD) is the most common form of chronic liver disease worldwide and is characterized by hepatic lipid accumulation in the absence of heavy alcohol consumption (de Alwis \& Day 2008). NAFLD is wildly associated with obesity, type 2 diabetes, dyslipidemia and the metabolic syndrome
๑ 2017 Society for Endocrinology Printed in Great Britain
(Samuel et al. 2010, Samuel \& Shulman 2012). In order to develop appropriate treatment, the knowledge of the molecular mechanisms underlying the development of NAFLD is essential. The largest contributor to liver steatosis is dysregulated hepatic de novo lipogenesis (DNL) (Fabbrini et al. 2010). DNL is a process in which 
the cell makes fatty acids from nonfat materials and liver is the most important organ for DNL (Lawes \& Gilbert 1877). Several transcription factors, including sterol regulatory element-binding proteins (SREBPs), liver $\mathrm{X}$ receptor (LXR) and carbohydrate response elementbinding protein (ChREBP) regulate the expression of genes involved in DNL in the liver (Iizuka \& Horikawa 2008, Ferre \& Foufelle 2010, Strable \& Ntambi 2010, Ducheix et al. 2011). These transcriptional factors ultimately affect the expression of key enzymes for DNL, which include that fatty acid synthase (FAS) (Jensen-Urstad \& Semenkovich 2012); and stearoylCoA desaturase 1 (SCD1) (Ntambi 1992). Given that $26 \pm 7 \%$ of hepatic triglycerides are derived from DNL in humans with NAFLD (Donnelly et al. 2005), decreased DNL in liver is a potential and interesting target for the treatment of NAFLD. Therefore, a better knowledge of the regulation of the key enzymes that control DNL in liver, namely FAS and SCD1, may in the future help the development of potential therapeutic approaches for NAFLD.

MicroRNAs (miRNA) is a new class of small, noncoding RNAs that regulate gene expression at the posttranscriptional level by binding, in most cases, to the 3'-untranslated region (UTR) of target genes and inhibiting translation or causing mRNA cleavage (Ambros 2001, Bartel 2004, He \& Hannon 2004, Wilfred et al. 2007). Previous work suggested that microRNAs are implicated in the process of NAFLD (Jin et al. 2009, Hoekstra et al. 2012, Feng et al. 2014). It is intriguing that circulating and liver miR-122 plays a role of physiological significance in the biology of NAFLD (Pirola et al. 2013, Miyaaki et al. 2014, Pirola et al. 2015). In addition, miR-185 significantly decreases the mRNA levels of Fas and sterol regulatory element-binding protein 1c (Srebp1c) and plays an important role in regulating fatty acid metabolism (Wang et al. 2014). Our previous study indicated that dietary deprivation of leucine suppresses lipid accumulation in the liver by downregulating the expression of FAS in a GCN2-dependent manner (Guo $\&$ Cavener 2007). The involvement of microRNA in this regulation, however, has not been reported. In the present study, we demonstrated that leucine deprivation inhibits FAS and SCD1 expression via GCN2/ATF4/miR-212-5p axis with results of decreased TG accumulation in hepatocytes. These findings suggested that nutritional or pharmacological modulation of miR-212-5p-FAS/ SCD1 axis could be potential therapeutic approaches for treating NAFLD.

\section{Materials and methods}

\section{Animals and treatment}

Male 8- to 10-week-old C57BL/6J mice were purchased from the Model Animal Research Center of Nanjing University (Nanjing, China), and fed a leucine-deficiency diet for 7 days. Mice were maintained on a $12 \mathrm{~h}$ light/ darkness cycle at $25^{\circ} \mathrm{C}$ and provided with free access to tap water. The Institutional Animal Care and Use Committee of the Institute for Nutritional Sciences (Shanghai, China) approved all the animal-related experimental procedures in this study (permit number: INS09-1001).

\section{Cell culture and treatments}

Mouse primary hepatocytes were prepared from livers of male C57BL/6J mice as described previously (Wang et al. 2009). Mouse primary hepatocytes were maintained in Dulbecco's Modified Eagle's medium (DMEM) with $25 \mathrm{mmol} / \mathrm{L}$ glucose from Gibco, $10 \%$ FBS, $50 \mathrm{mg} / \mathrm{mL}$ penicillin and streptomycin at $37^{\circ} \mathrm{C}$, and $5 \% \mathrm{CO}_{2}-95 \%$ air. miRNA double-stranded mimics for miR-212-5p or miR-212-5p inhibitors were purchased from GenePharma (Shanghai, China) with the following sequences: miR-212-5p mimics (5'-accuuggcucuagacugcuuacu- $3^{\prime}$ ) and miR-212-5p inhibitors (5'-aguaagcagucuagagccaaggu-3', 2'Ome modification). Primary hepatocytes were transfected with miR-212-5p mimics, inhibitors or negative control for $48 \mathrm{~h}$.

\section{Bioinformatic analysis}

miRanda and miRBase Release 16.0 were used to identify the potential putative targets of miR-212-5p and miR-212-3p.

\section{DNA constructs and mutagenesis}

The DNA fragment encoding miR-212 pre-miRNA was amplified using mouse genomic DNA as the PCR template and inserted into the expressing vector named pShuttleCMV. DNA fragments of 3 '-untranslated regions (UTRs) from FAS and SCD1 containing potential miR-212-5p binding sites were amplified and cloned into Xba I site immediately downstream of the stop codon in the pGL3promoter vector from Promega. Mutated FAS and SCD1 3 'UTR reporter plasmids were constructed using the overlapping four-primer PCR to produce mutated $3^{\prime} \mathrm{UTR}$ pGL3 reporter plasmid.

Published by Bioscientifica Ltd. 


\section{Luciferase assay}

Human embryonic kidney (HEK) 293 cells were cultured in 96-well plates and at $20 \%$ confluence, $150 \mathrm{ng}$ of plasmid containing either the mutated or the wild-type the 3'UTR sequence were transfected using Lipofectamine 2000 Transfection Reagent and Opti-MEM from Invitrogen. Renilla plasmid (5 ng) was cotransfected as the transfection control. The cells were cotransfected with either the negative control or the mimic (50 ng) and incubated for $24 \mathrm{~h}$. Cells were then lysed using $1 \times$ Passive lysis buffer from Promega and luciferase activity was measured using a luminometer from Amersham Buchler (Braunschweig, Germany) according to the manufacturer's instructions. Firefly luciferase values were normalized to those of Renilla luciferase.

\section{Generation and administration of recombinant adenoviruses}

The recombinant adenoviruses used for miR-212 expression was generated using AdEasy Vector System from Qbiogene (CA, USA). Viruses were diluted in PBS and administered at a dose of $1 \times 10^{7} \mathrm{pfu} /$ well in 12 -well plate or $5 \times 10^{8} \mathrm{pfu} /$ mice through tail vein injection.

\section{RNA isolation and relative quantitative PCR}

Total RNA was prepared from frozen tissues with TRIZOL from Invitrogen reagent. For mRNA detection, Two micrograms of RNA were reversely transcribed with random primer and M-MLV reverse transcriptase from Takara. Quantitative amplification by PCR was carried out using SYBR Green I Master Mix reagent from Takara by ABI 7900 system. GAPDH was used as an internal control for each gene of interests. For miRNA detection, polyA tail was added to RNase-free DNase-digested total RNA using the E. coli polyA polymerase from NEB (Beverly, MA, USA). One microgram of the tailed total RNA was reverse transcribed with miR dTRT primer (5'-cgactcgatcca gtctcagggtcc gaggtattcgatc gagtcgcactt tttttttttv-3'). SYBR Green qRT-PCR was used to assay miRNA expression with the specific forward primers and the universal reverse primer complementary (Hi-rev: 5'-ccagtctcagggtccgaggtattc-3') to the anchor primer. U6 was used as internal control.

\section{Western blotting}

Mouse liver and cell extracts were lysed by RIPA lysis buffer (150 mmol/L Tris-HCl, 50 mmol/L NaCl, 1\% NP-40, 0.1\% tween 20), and centrifuged at $15,000 \boldsymbol{g}$ for $20 \mathrm{~min}$. Then, the supernate was mixed with isometric sodium dodecyl sulfate (SDS) buffer (125 mmol/L, Tris- $\mathrm{HCl}$ ( $\mathrm{pH}$ 6.8), $10 \%$ mercaptoethanol (v/v), 4\% SDS (w/v), 20\% glycerol (v/v) and $0.002 \%$ bromophenol blue). The mixture was heated for $10 \mathrm{~min}$ at $100^{\circ} \mathrm{C}$. Supernatants were subjected to $10 \%$ SDS-PAGE gels and were wet-blotted. The primary antibodies against FAS (BD Biosciences), SCD1 and SREBP1c (Santa Cruz Biotechnology), and ACTIN (Sigma) were incubated overnight at $4^{\circ} \mathrm{C}$ and visualized by ECL Plus from GE Healthcare. Band intensities were measured by Tanon-5500 Chemiluminescent Imaging System from Tanon Science \& Technology (Shanghai, China).

\section{Measurements of triglyceride (TG), cholesterol (TC) and free fatty acids (FFAs)}

Hepatic and cellular lipids were extracted with chloroformmethanol (Folch et al. 1957) and TG, TC and FFAs were determined using TG kit, TC kit (Jiancheng, Nanjing, China) and FFAs kit (Wako Pure Chemical Industries), respectively, according to the manufacturer's instructions. The values obtained were normalized to the total protein content and are expressed as $\mathrm{nmol} / \mu \mathrm{g}$ protein. Control and oleate sodium- $(200 \mu \mathrm{mmol} / \mathrm{L})$ treated cells and hepatic lipids were also evaluated for the levels of triglycerides in an identical manner. For hepatic lipid determination, the values obtained were normalized to the liver weight and are expressed as $\mathrm{nmol} / \mathrm{g}$ liver.

\section{Statistical analysis}

All data are expressed as means \pm s.e.m. Significant differences were assessed by two-tail Student's $t$-test or one-way ANOVA followed by the Student-Newman-Keuls test. $P<0.05$ was considered statistically significant.

\section{Results}

\section{Leucine deficiency induces the expression of miR-212}

Our previous study indicated that leucine deprivation inhibits lipogenesis in liver via downregulating FAS expression in the liver (Guo \& Cavener 2007). To explore the possible role of miRNAs in this process, we used TargetScan, PicTar and miRanda to predict the potential miRNAs targeting FAS. These potential microRNAs included miR-27a, miR-27b, miR-33, miR-130a, miR-132, miR-191, miR-212 and miR-214. Further study showed that miR-27a, miR-27b, miR-132, miR-191, miR-212

Published by Bioscientifica Ltd 
and miR-214 can significantly suppress the activity of FAS 3'UTR (Fig. 1A). Among them, miR-212 is the most effective miRNAs for the regulation of FAS 3'UTR. To further investigate the possible role of miR-212 in the process of leucine deprivation-suppressed FAS expression and TG accumulation, we examined the expression of miR-212 in the liver of mice fed a control diet or leucinedeficiency diet. The results showed that both miR-212-3p and miR-212-5p were increased in the livers of mice fed a leucine-deficiency diet (Fig. 1B). However, it is miR-212-5p, not miR-212-3p, that significantly suppressed the activity of FAS 3'UTR (Fig. 1C).

\section{miR-212-5p directly targets FAS and SCD1}

Given that miR-212-5p, but not miR-212-3p, targets FAS, the effect of miR-212-5p on lipid metabolism was further investigated. FAS and SCD1, both key enzymes for lipogenesis in liver, are predicted to be direct targets of miR-212-5p (Fig. 2A). To verify this, we generated Renilla luciferase reporter plasmids containing miR-212-5p binding sites in the 3'UTRs of mouse FAS and SCD1. A reporter gene assay performed in HEK293 cells revealed miR-212-5p-dependent repression of luciferase activity from these constructs. Mutation of the miR-212-5p-target sites abrogated miR-212-mediated reduction in luciferase activity (Fig. 2B). To determine whether miR-212-5p can target endogenous FAS and SCD1, primary mouse hepatocytes were isolated and infected with miR-212-5p mimics or miR-212-5p inhibitor or negative control. We found that miR-212-5p mimics significantly increased the expression of miR-212-5p in mouse primary hepatocytes (Fig. 2C). Overexpression of miR-212-5p did not influence the mRNA levels of Fas and $S c d 1$ (Fig. 2D), but inhibited the protein levels of FAS and SCD1 relative to negative control treatment while the protein level of SREBP1c had no difference (Fig. 2E). Conversely, miR-212-5p inhibitor significantly decreased the expression of miR-212-5p (Fig. 2F). Inhibition of miR-212-5p also did not influence the mRNA levels of Fas and Scd1 (Fig. 2G), but significantly increased the protein levels of FAS and SCD1 while the protein level of SREBP1c had no difference (Fig. 2H).

\section{miR-212-5p suppresses triglyceride accumulation in primary hepatocytes}

Leucine deprivation suppresses the TG accumulation in liver, which is accompanied by elevated miR-212-5p. In the present study, the miR-212-5p mimics and adenovirus-mediated miR-212-5p overexpression were used to determine the effect of miR-212-5p on TG accumulation in mouse primary hepatocytes under basic or oleatic sodium-stimulated conditions. Results showed

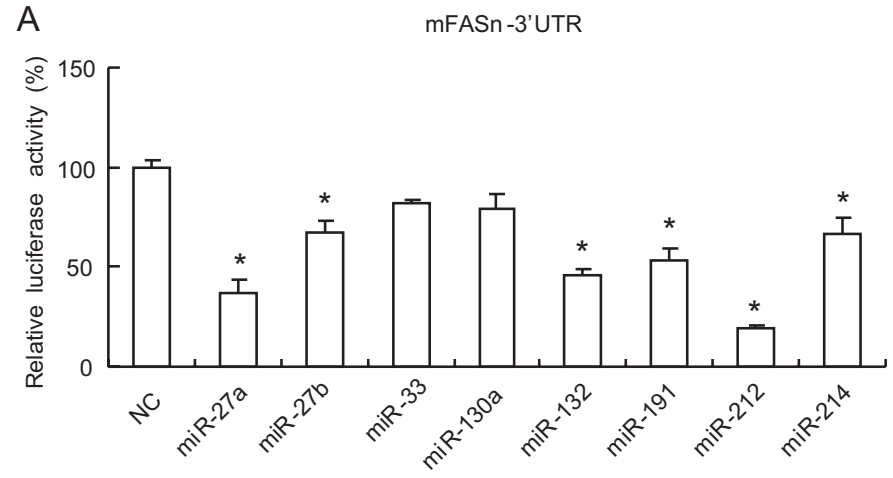

B
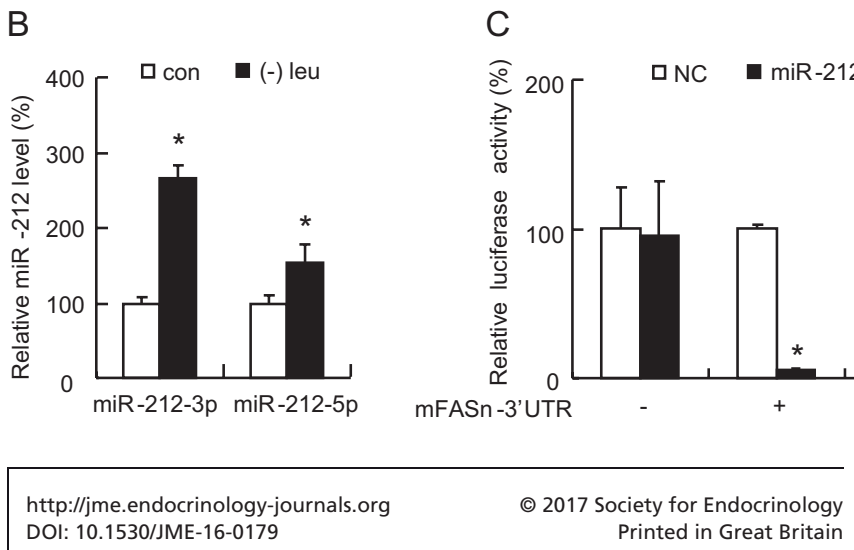

Figure 1

miR-212-5p but not miR-212-3p inhibits the activity of FAS $3^{\prime}$ UTR. (A) Luciferase activity assay for FAS 3'UTR by miR-27a, miR-27b, miR-33, miR-130a, miR-132, miR-191, miR-212 and miR-214 in 293T cells $(n=3)$. (B) Expression of miR-212-3p and miR-212-5p in the livers of mice fed a leucine-deficiency diet ((-) leu) or control diet (con) for 7 days $(n=6)$. (C) Effect of miR-212-5p or miR-212-3p on activity of FAS-3'UTR in 293T cell $(n=3)$. Means \pm S.E.M.S shown are representative of at least two independent in vitro experiments, with the number of each group in each experiment indicated. Statistical significance was determined by two-tailed Student's $t$-test for the effect of miR-212-5p mimics or miR-212-3p mimics vs control $\left({ }^{*} P<0.05\right)$. 
A

\begin{tabular}{ll}
\hline FAS-3'UTR: & 5'-CAGTGGAGGCAGGAGCCAAAC-3 \\
miR-212-5p: & 3'- CAUUCGUCAGAUCUCGGUUCCA-5' \\
FAS-3'UTR-Mut: & 5'- CUGAGCUGUUACCUTATGGCCC-3' \\
\hline & \\
\hline SCD1-3'UTR: & 5'-CUAUACAGAGAG--AGCCAAGGA-3' \\
miR-212-5p: & 3'-CAUUCGUCAGAUCUCGGUUCCA-5' \\
SCD1-3'UTR-Mut: 5'- CUAUACAGAGAG--ATATGGCCA-3'
\end{tabular}

C

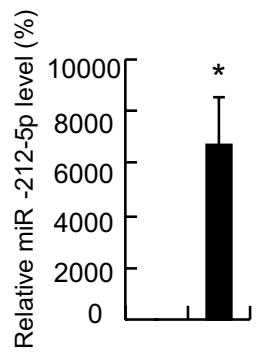

D

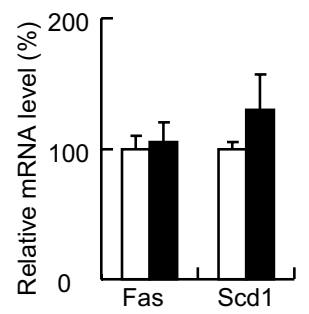

E

B
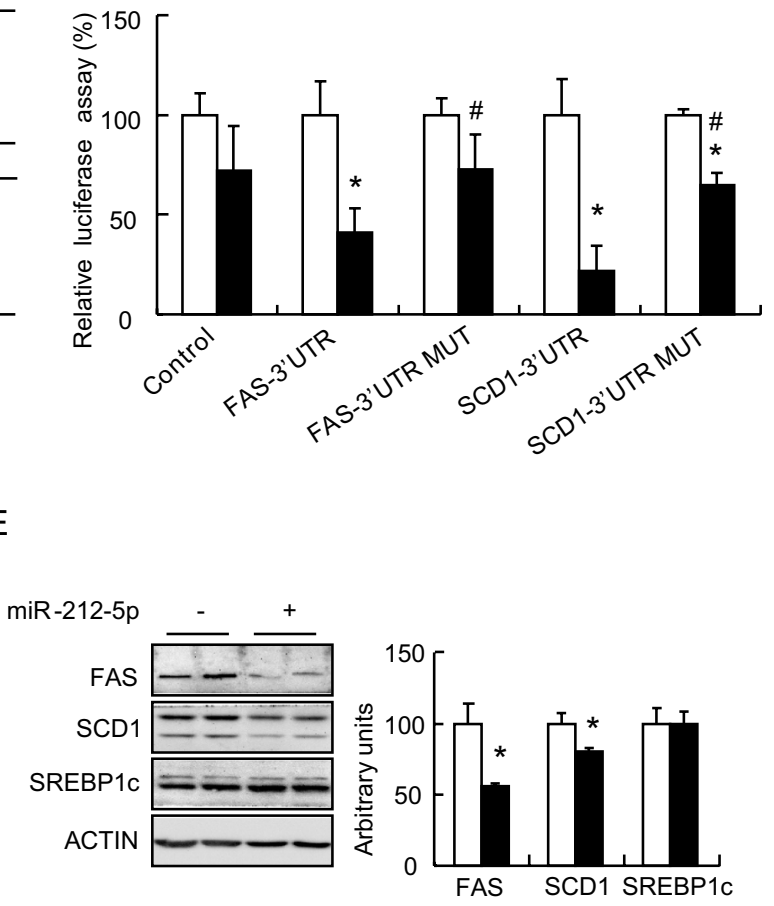

$\mathrm{F}$

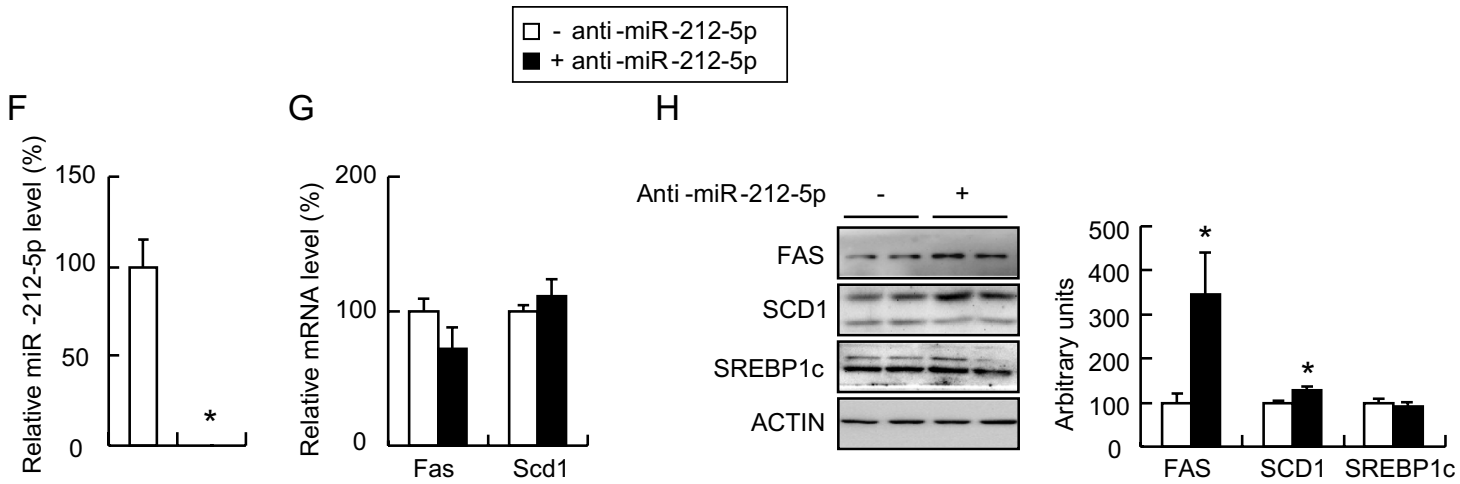

$\square$ - miR-212-5p mimics

+ miR-212-5p mimics

Figure 2

miR-212-5p directly targets FAS and SCD1 in mouse primary hepatocytes. (A) miR-212-5p binding site on the mouse FAS 3'UTR and mouse SCD1 $3^{\prime} U T R$ is shown, and the mutant of FAS $3^{\prime}$ UTR (FAS-3'UTR-Mut) and the mutant of SCD1 $3^{\prime}$ UTR (SCD1-3'UTR-Mut) are shown. (B) In vitro luciferase reporter assay in HEK293 cells. miR-212-5p mimics or negative control was cotransfected with the pGL3-3'-UTR reporter plasmids containing the FAS-3'UTR, SCD1$3^{\prime}$ UTR, FAS-3'UTR-Mut or SCD1-3'UTR-Mut ( $\left.n=3\right)$. (C, D and E) Mouse primary hepatocytes were transfected with miR-212-5p mimics for 48h ( $n=6$ ). $(F, G$ and $H)$ Mouse primary hepatocytes were transfected with miR-212-5p inhibitor for $48 \mathrm{~h}(n=6)$. (C and F) Expression of miR-212-5p. (D and G) Fas and Scd1 mRNA levels. (E and H) FAS, SCD1 and SREBP1c protein levels (left, Western blot; right, quantitative measurements of FAS, SCD1 and SREBP1c protein relative to ACTIN). Means \pm S.E.M.S shown are representative of at least two independent in vitro experiments, with the number of each group in each experiment indicated. Statistical significance was determined by two-tailed Student's $t$-test for the effect of miR-212-5p mimics or miR-212-5p inhibitor vs control $\left({ }^{*} P<0.05\right)$.

that miR-212-5p mimics significantly decreased the TG accumulation in primary hepatocytes under both basic and oleatic sodium-stimulated conditions (Fig. 3A). For the convenience in investigating the role of miR-212-5p in lipid metabolism in vivo, we constructed the adenovirusmediated miR-212-5p overexpression (Ad-miR-212) system. Overexpression of miR-212-5p in primary hepatocytes is about 4-fold with Ad-miR-212 (Fig. 3B) 

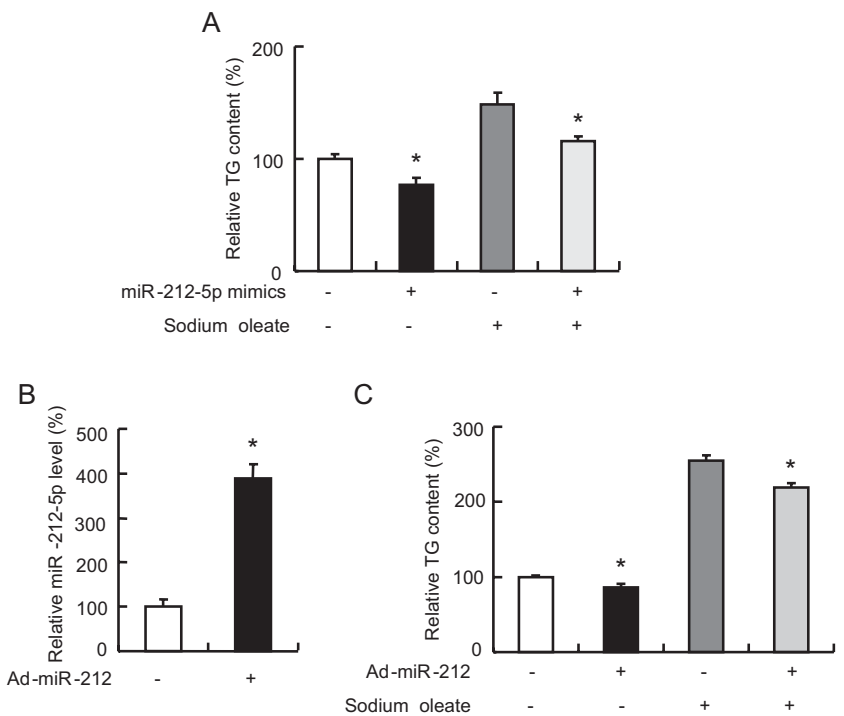

Figure 3

miR-212-5p significantly inhibits TG accumulation in mouse primary hepatocytes. (A) Assay of the TG content of mouse primary hepatocytes transfected with miR-212-5p mimics or control for $48 \mathrm{~h}$ with or without the $200 \mu \mathrm{M}$ sodium oleate treatment $(n=4)$. (B) Expression of miR-212-5p in mouse primary hepatocytes infected with Ad-miR-212 for $48 \mathrm{~h}(n=6)$. (C) Assay of the TG content of mouse primary hepatocytes transfected with Ad-miR-212 or Ad-GFP for $48 \mathrm{~h}$ with or without the $200 \mu \mathrm{M}$ sodium oleate treatment $(n=4)$. Means \pm S.E.M.s shown are representative of at least two independent in vitro experiments, with the number of each group in each experiment indicated. Statistical significance was determined by two-tailed Student's $t$-test for the effect of miR-212-5p mimics or Ad-miR-212 vs control $(* P<0.05)$.

and also significantly inhibited the TG accumulation in primary hepatocytes under both conditions (Fig. 3C).

\section{Hepatic overexpression of miR-212-5p suppresses TG accumulation in liver via inhibiting lipogenesis}

Based on the above results, we speculated that miR-212-5p might also be involved in the regulation of hepatic lipid metabolism in vivo. To test this possibility, mice were injected with Ad-miR-212 or Ad-GFP. Actually, miR-212-5p mRNA levels were significantly increased about 3 -fold in the livers of mouse injected with Ad-miR-212 compared with control mice (Fig. 4A) while there were no difference in the expression of miR-212 in other tissues such as adipose tissue and brown adipose tissue (Supplementary Fig. 1A and B, see section on supplementary data given at the end of this article). Injection of Ad-miR-212 for 7 days did not influence body weight and food intake of mice (Fig. 4B and C). However, the liver to body weight ratio was significantly decreased in the mice injected with Ad-miR-212 compared with that in control mice (Fig. 4D). Furthermore, the TG content and the level of FFAs in the livers of mice injected with Ad-miR-212 were significantly decreased compared with those of Ad-GFP mice while the cholesterol (TC) content has no change (Fig. 4E). Moreover, the serum TG content and TC content were significantly decreased in the livers of mice injected with Ad-miR-212 compared with those of control mice although the serum level of FFAs has no difference (Fig. 4F). Consistent with these changes, lipid accumulation was significantly decreased in the livers of Ad-miR-212 mice, as demonstrated by Oil Red O staining and H\&E staining (Fig. 4G). Hepatic lipogenesis, $\beta$-oxidation, and uptake and secretion of fatty acids contribute to the total TG content in the liver. For this reason, we examined the mRNA levels of genes related to these processes. These included acetyl CoA carboxylase 1 (ACC1) and FAS, which together catalyze the rate-limiting step in the production of palmitate 16:0; stearoyl-CoA desaturase (SCD), which catalyzes the synthesis of oleic acid (18:1, n-9); ATP-citrate lyase (ACL), which catalyzes the conversion of citrate to $\mathrm{CoA}$ and oxaloacetate; and sterol receptor element-binding protein 1c (SREBP1c) and peroxisome proliferator-activated receptor $\gamma$ (PPAR $\gamma$ ), which are key regulators of lipogenic genes including FAS and SCD1. We found that the Fas and Scd1 mRNA levels were significantly decreased by Ad-miR-212 in the livers of $\mathrm{C} 57 \mathrm{BJ} / 6 \mathrm{~L}$ mice, while there were no differences in Srebp1c, Ppary, Acc1 and Acl mRNA levels (Fig. 4H). Otherwise, impaired $\beta$-oxidation of fatty acids is another contributor of liver steatosis (Kersten et al. 1999, Leone et al. 1999). Peroxisome proliferator-activated receptor- $\alpha$ (PPAR $\alpha$ ), a key regulator of $\beta$-fatty acid oxidation, peroxisome proliferator-activated receptor c coactivator $1 \alpha(\mathrm{PGC} 1 \alpha)$, a cofactor of PPAR $\alpha$, and CPT1, a direct target of PPAR $\alpha$, were not changed in the livers of mice injected with Ad-miR-212 (Fig. 4I). In addition to triglyceride synthesis and $\beta$-oxidation, misregulation of triglyceride uptake and secretion could also contribute to fatty liver (Bradbury 2006). We therefore examined the genes related to the secretion of fatty acids, including apolipoprotein $\mathrm{B}(\mathrm{ApoB})$, apolipoprotein $\mathrm{E}$ (ApoE) and apolipoprotein $\mathrm{H}$ $(\mathrm{ApoH})$ and the genes related to the uptake of fatty acids, including fatty acid transport protein (FATP), fatty acidbinding protein (FABP) and fatty acid translocase (CD36). The results showed that only Cd36 was significantly increased by Ad-miR-212 (Fig. 4J), which contributes to increased TG accumulation in livers. By considering the suppressive effect of Ad-miR-212 on TG accumulation, it is assumed that the suppressed lipogenesis is the main contributor in this process. As expected, the FAS and http://jme.endocrinology-journals.org DOI: 10.1530/JME-16-0179
() 2017 Society for Endocrinology Printed in Great Britain
Published by Bioscientifica Ltd 
A

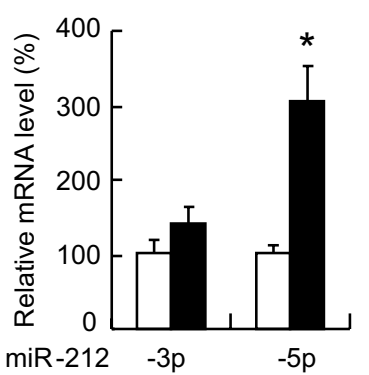

E

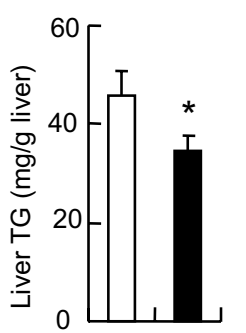

G

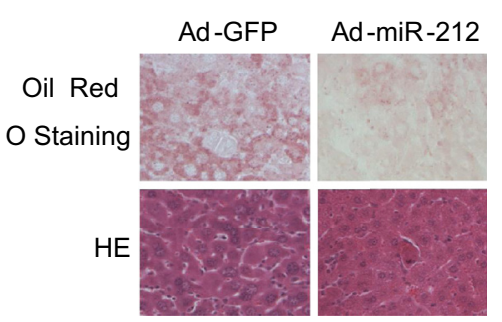

J
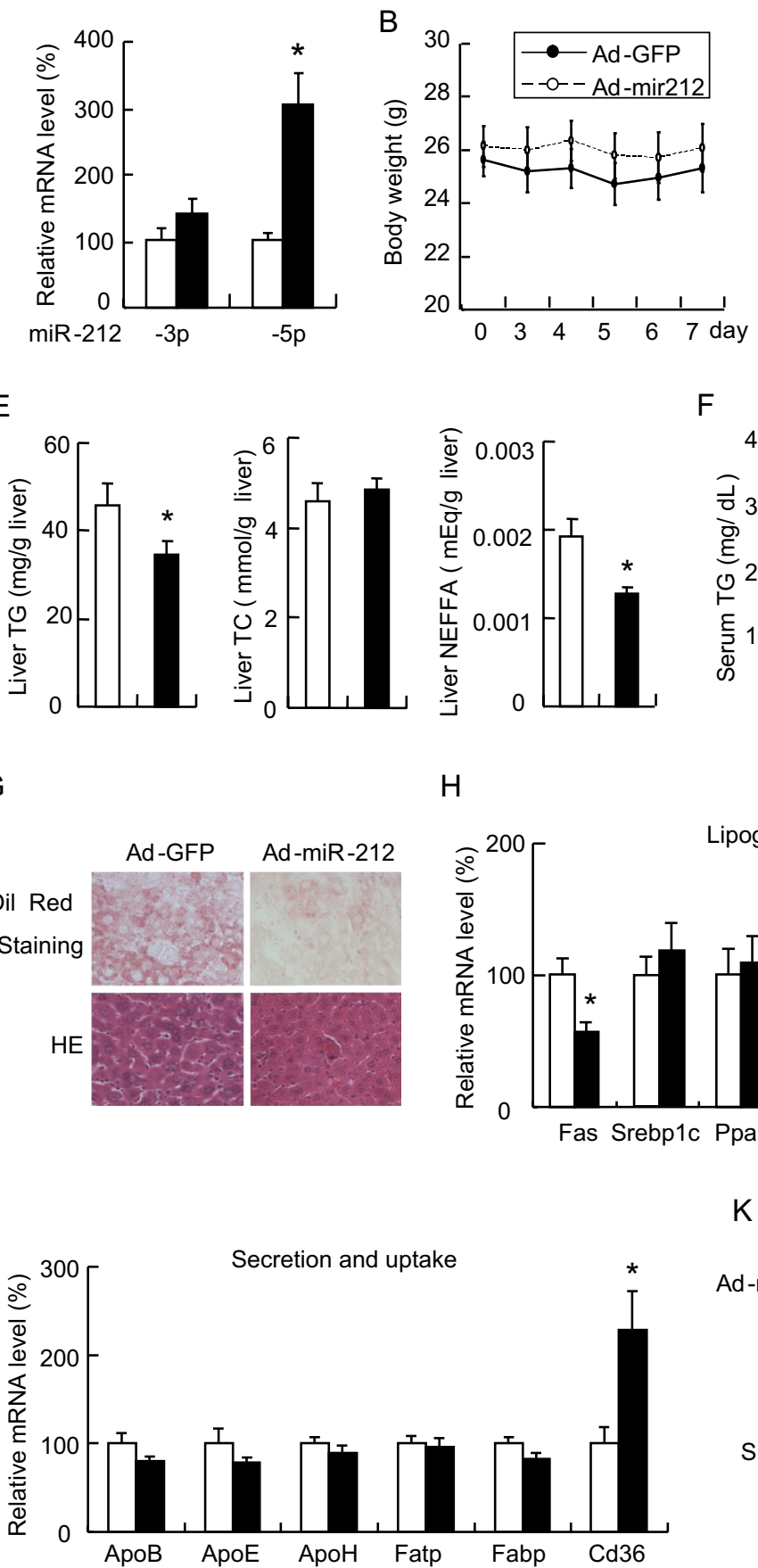

$\mathrm{H}$

C
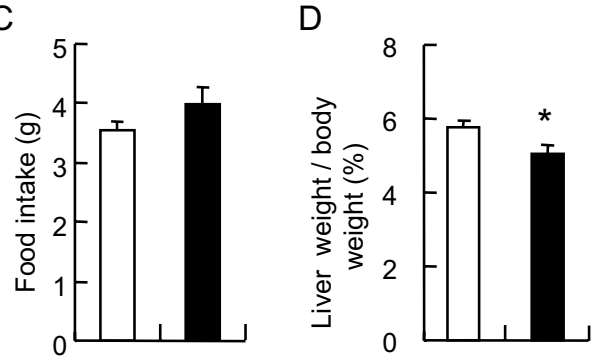

$\mathrm{F}$
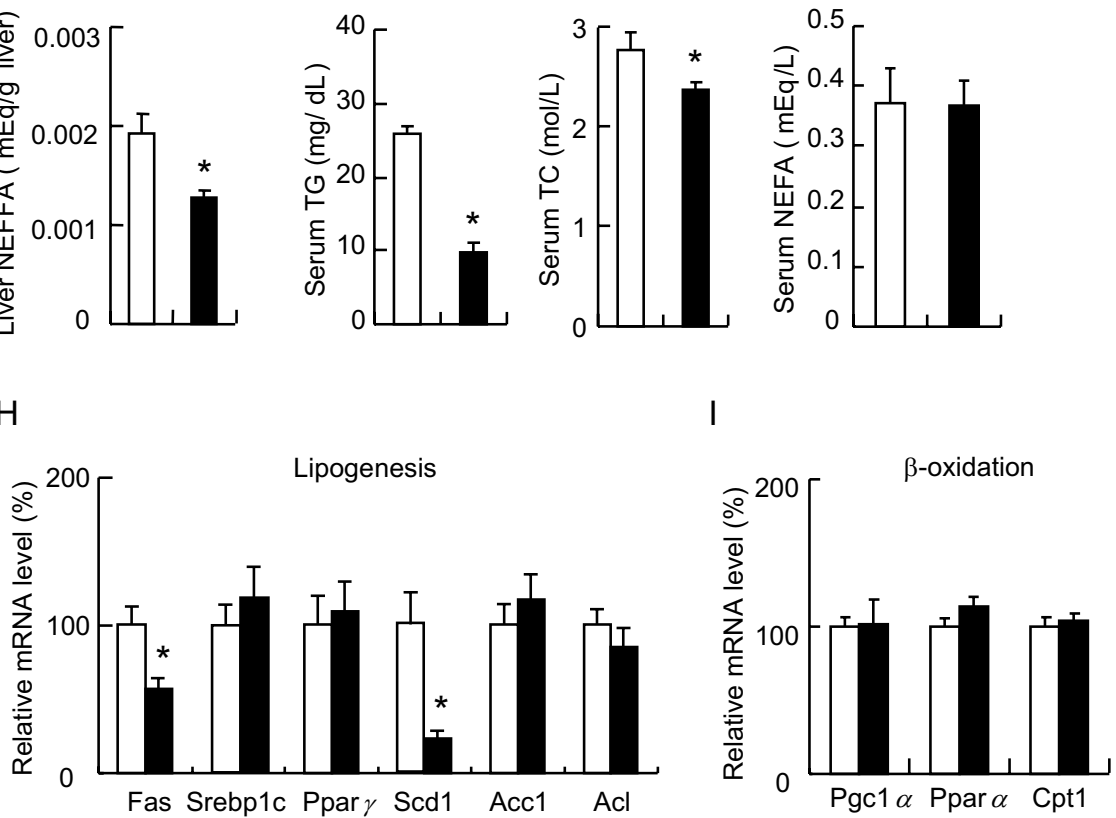

K
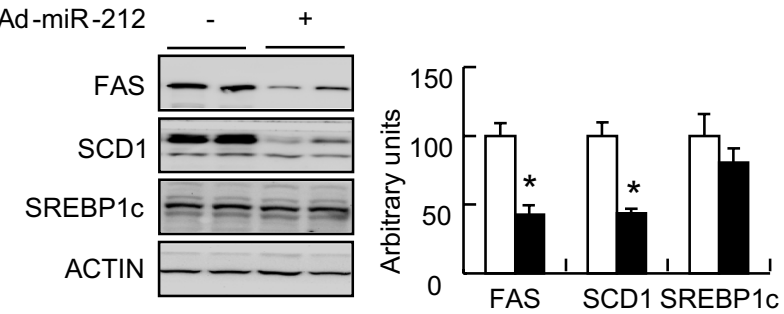

Figure 4

miR-212-5p significantly suppresses the expression of FAS and SCD1 and inhibits the lipid accumulation in the livers of mice. (A, B, C, D, E, F, G, $H, I, J$ and K) eight- to ten-week-old male mice were injected with Ad-miR-212 (+Ad-miR-212) or Ad-GFP $(-A d-m i R-212)$ for 7 days $(n=6)$. (A) miR-212-5p and miR-212-3p mRNA levels. (B) Body weight. (C) Food intake. (D) Ratio of liver weight to body weight (\%). (E) Liver TG, TC and FFA content. (F) Serum TG, TC and FFA content. (G) Representative photomicrographs of liver stained with Oil Red O (top) or Hematoxylin-Eosin (H\&E) (bottom). (H) Fas, Srebp1C, Ppary, Scd1, Acc1 and Acl mRNA levels. (I) Pgc1a, Ppara and Cpt1 mRNA levels. (J) ApoB, ApoE, ApoH, Fatp, Fabp and Cd36 mRNA levels. (K) FAS, SCD1 and SREBP1c protein levels (left, Western blot; right, quantitative measurements of FAS, SCD1 and SREBP1C protein relative to ACTIN). Means \pm s.E.M.S shown are representative of two independent in vivo experiments, with the number of each group indicated. Statistical significance was determined by two-tailed Student's $t$-test for the effect of Ad-miR-212 vs control $\left({ }^{*} P<0.05\right)$.

$\begin{array}{lr}\text { http://jme.endocrinology-journals.org } & \text { ○ } 2017 \text { Society for Endocrinology } \\ \text { DOI: } 10.1530 / J M E-16-0179 & \text { Printed in Great Britain }\end{array}$

Published by Bioscientifica Ltd 
SCD1 protein levels were significantly decreased in the livers of Ad-miR-212-treated mice compared with those in the control mice, while the SREBP1c protein level has no difference (Fig. 4K).

Above data suggested that miR-212 regulate lipid metabolism in WT mice, based on this, we speculated that miR-212 might be involved in the regulation of liver steatosis in diet-induced NAFLD. To test this possibility, 4-week-old male mice were fed with HFD for 13 weeks and then injected with Ad-miR-212 or Ad-GFP. Consistent with WT mice, we found that overexpressed miR-212 dramatically decreased lipid accumulation in livers of HFD mice, which was also mediated by inhibiting the expression of FAS and SCD1 (Supplementary Fig. 2).

\section{miR-212-5p inhibitor reverses leucine deprivation-} suppressed TG accumulation in primary hepatocytes

Our previous study showed that leucine deprivation decreased TG accumulation via suppressing lipogenesis in the liver (Guo \& Cavener 2007). We further explore the possibility of miR-212-5p-mediated effect of leucine deprivation on TG accumulation in primary hepatocytes.
Above data indicated that leucine deprivation induced the expression of miR-212-5p, which plays a key role in the regulation of the expression of FAS and SCD1, as well as TG accumulation. We speculated that increased miR-212-5p expression may contribute to the suppressed lipogenesis and TG accumulation under the condition of leucine deprivation. To test this hypothesis, we knocked down miR-212-5p expression using miR-212-5p inhibitor in primary hepatocytes (Fig. 5A). miR-212-5p knockdown effectively reversed the effect of leucine deprivation on the expression of FAS and SCD1 in primary hepatocytes (Fig. 5B and C). Furthermore, the TG content was also significantly reversed in the group of miR-212-5p inhibitor with leucine deprivation compared with the group of leucine deprivation (Fig. 5D).

\section{miR-212-5p is induced by leucine deprivation via GCN2/ATF4 pathway}

Although miR-212-5p is involved in leucine deprivationinduced decreased TG accumulation and suppressed lipogenesis, the mechanisms underlying leucine deprivation regulating the expression of miR-212-5p

\begin{tabular}{|l}
\hline$\square$ Control \\
$\square$ (-) leu \\
$\square \quad(-)$ leu +anti -miR-212-5p
\end{tabular}

A

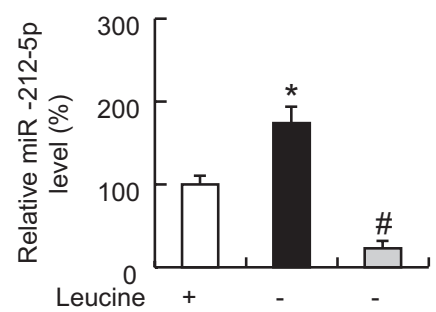

anti-miR-212-5p - $\quad$ - $\quad+$

C

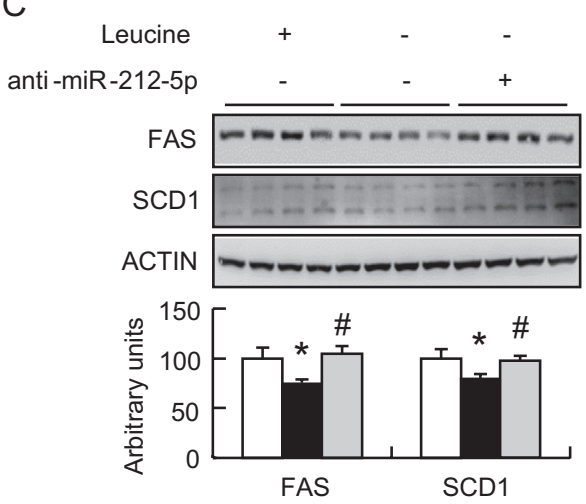

$\mathrm{B}$

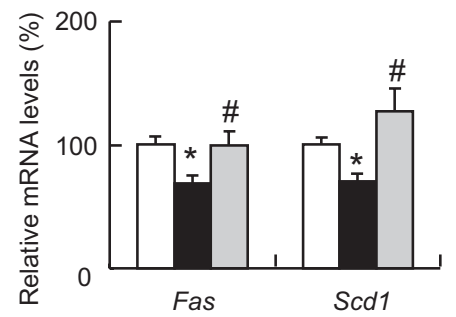

D

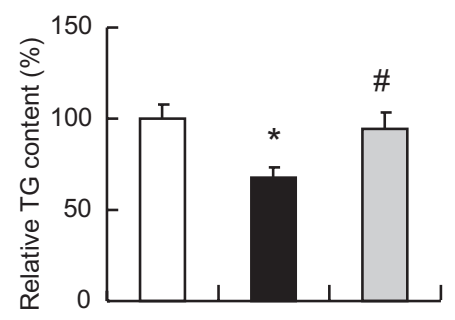

\section{Figure 5}

Inhibition of miR-212-5p can reverse the effect of leucine deprivation on expression of FAS and SCD1, as well as TG accumulation. (A, B, C and D) Mouse primary hepatocytes were transfected with miR-212-5p inhibitor with or without leucine deprivation treatment $(n=4)$. (A) miR-212-5p mRNA level. (B) Fas and Scd1 mRNA levels. (C) FAS and SCD1 protein levels (Upper, Western blot; lower, quantitative measurements of FAS and SCD1 protein relative to ACTIN). (D) TG content. Means \pm S.E.M.S shown are representative of two independent in vitro experiments, with the number of each group indicated. Statistical significance was determined by two-tailed Student's $t$-test or one-way ANOVA followed by the SNK test for the effect of leucine deprivation vs control ( $\left.{ }^{*} P<0.05\right)$, or the effect of miR-212-5p inhibitor vs negative control under the condition of leucine deprivation ( $\left.{ }^{P}<0.05\right)$. 
are largely unclear. GCN2 is a serine protein kinase that functions as a sensor for amino acid deprivation (Hinnebusch 1994), suggesting the possible involvement of GCN2 in the regulation of miR-212-5p expression during leucine deprivation. To test this possibility, we examined miR-212-5p expression in primary hepatocytes of GCN2 knockdown maintained on a control or leucine deprivation medium for $48 \mathrm{~h}$. As predicted, the expression of GCN2 was decreased in shGCN2-treated cells, as well as ATF4, a downstream target gene of GCN2 (Fig. 6A). Leucine deprivation-induced miR-212-5p expression was largely blocked in primary hepatocytes with GCN2 knockdown (Fig. 6B). GCN2/ATF4 pathway is critical to cell survival in response to amino acid deprivation (Ye et al. 2010, Averous et al. 2011, Wang et al. 2013), suggesting that the leucine deprivation-induced GCN2/ATF4 activity might be involved in the regulation of miR-212-5p expression. To test this possibility, we examined whether the knockdown of ATF4 decreases leucine deprivationinduced miR-212-5p expression. As predicted, leucine deprivation-induced miR-212-5p expression was significantly blocked in primary hepatocytes with ATF4 knockdown under the condition of leucine deprivation (Fig. 6C and D).

\section{Discussion}

NAFLD usually begins with an aberrant fat accumulation in the hepatocytes due to metabolic imbalances such as increased DNL (Postic \& Girard 2008). Our previous study indicated that leucine deprivation suppresses hepatic DNL (Guo \& Cavener 2007). Previous work has suggested that microRNAs play a key role in the regulation of lipid accumulation in liver (Soh et al. 2013, Dai et al. 2016). We have been interested in the role of microRNAs in regulating lipogenesis, especially in the process of leucine deprivation-suppressed lipogenesis, in liver. In our current study, we concentrated on investigating the function of miR-212 on lipid metabolism. miR-212 was involved in tumorigenesis (Incoronato et al. 2011, Wei et al. 2014,
A

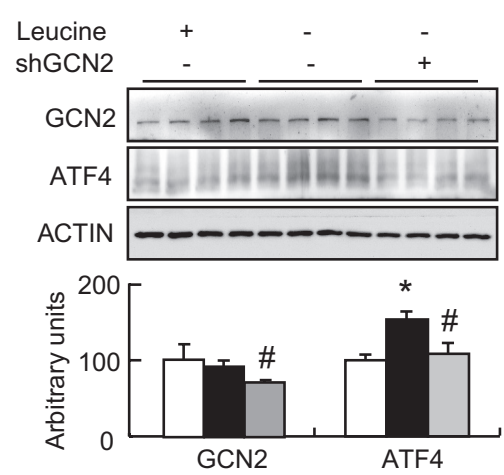

C

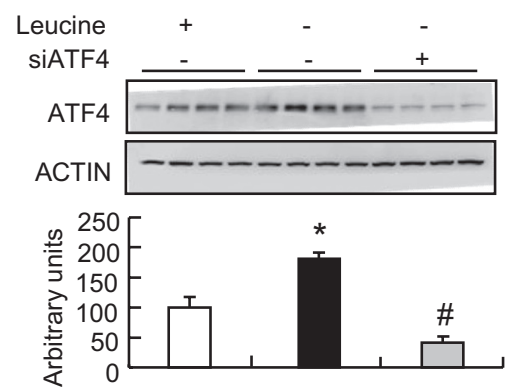

B

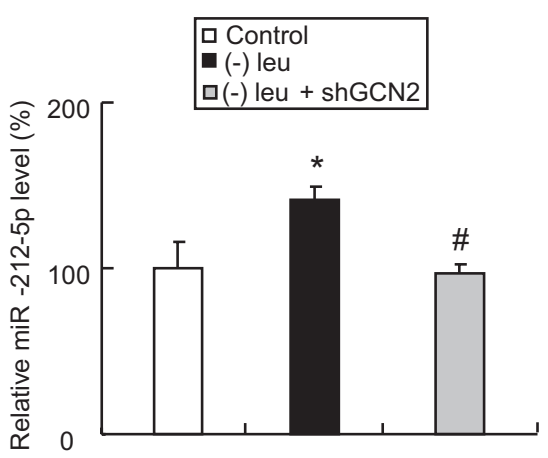

$\mathrm{D}$

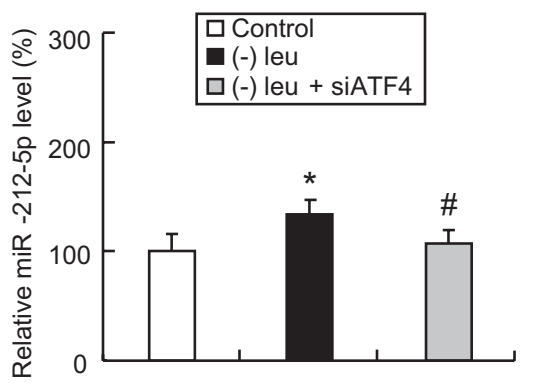

E

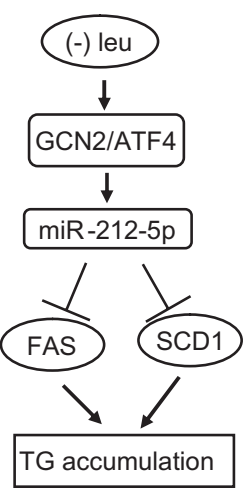

Figure 6

Leucine deprivation induces the expression of miR-212-5p in a GCN2/ATF4-dependent pathway. (A and B) Mouse primary hepatocytes were transfected with shGCN2 or negative control with or without leucine deprivation treatment $(n=4)$. (C and D) Mouse primary hepatocytes were transfected with siATF4 or negative control with or without leucine deprivation treatment $(n=4)$. (A) GCN2 and ATF4 protein levels (Upper, Western blot; lower, quantitative measurements of GCN2 and ATF4 protein relative to ACTIN). (B and D) miR-212-5p mRNA level. (C) ATF4 protein level (Upper, Western blot; lower, quantitative measurements of ATF4 protein relative to ACTIN). (E) Working model. Means \pm S.E.M.S shown are representative of two independent in vitro experiments, with the number of each group indicated. Statistical significance was determined by two-tailed Student's t-test or one-way ANOVA followed by the SNK test for the effect of leucine deprivation vs control $\left({ }^{*} P<0.05\right)$, or the effect of shGCN2 or siATF4 vs control under the condition of leucine deprivation $(\# P<0.05)$.

http://jme.endocrinology-journals.org DOI: 10.1530/JME-16-0179
C 2017 Society for Endocrinology Printed in Great Britain
Published by Bioscientifica Ltd 
Liang et al. 2013, Jiang et al. 2014, Ma et al. 2014) and mouse mammary gland development (Ucar et al. 2010). Though miR-212 can target Cyclin D1 (Jiang et al. 2014), which is involved in the regulation hepatic lipogenesis (Hanse et al. 2012), a direct effect of miR-212 on hepatic lipogenesis has not been described previously. Our work showed that miR-212 is a potential microRNA which could target 3'UTR of FAS and SCD1. The expression of miR-212-5p and miR-212-3p was increased in the livers of mice fed a leucine-deficiency diet compared with those of control mice, which suggested that miR-212 might be involved in leucine-deficiency-regulated hepatic lipogenesis. Further study showed that miR-212-5p, but not miR-212-3p, targets FAS, implying that miR-212-5p might be involved in hepatic lipogenesis. Furthermore, miR-212-5p directly target FAS and SCD1 to suppress TG accumulation in vitro and in vivo. What is more, our study indicated that the increased expression of miR-212-5p was induced by leucine deprivation-dependent GCN2/ATF4 signaling.

microRNA.org (http://www.microrna.org) is a comprehensive resource of microRNA target predictions, which are based on the development of a miRanda algorithm (Betel et al. 2008). Using FAS 3'UTR as target, the predicted microRNAs include miR-27a, miR-27b, miR-33, miR-130a, miR-132, miR-191, miR-212 and miR-214. Furthermore, miR-212 is most effective microRNA which significantly suppresses the activity of FAS 3'UTR. miR-212-5p (accession no. MIMAT0017053) and miR-212-3p (accession no. MIMAT0000659) are two isoforms from the same gene in mouse with different sequences. Though both miR-212-5p and miR-212-3p are predicted microRNAs-targeted FAS, only miR-212-5p, but not miR-212-3p, significantly inhibits the activity of FAS 3 'UTR. On the other hand, leucine deprivation induced the expression of miR-212-5p and miR-212-3p. The results implied that miR-212-5p is the main isoform suppressing the expression of FAS in response to leucine deprivation while whether miR-212-3p plays a role in this process needs further investigation in the future.

FAS is a large multi-subunit protein that synthesizes the sixteen-carbon saturated fatty acid palmitate through the sequential addition of two carbon units at a time, with the carbons donated by malonyl-CoA. SCD is a delta-9 desaturase that catalyzes the conversion of saturated fatty acids to their monounsaturated fatty acid (MUFA) counterparts. Both FAS and SCD1 are key enzymes for $D N L$ in liver (Strable \& Ntambi 2010). Using bioinformatics tools, we found that both FAS and SCD1 are the target genes of miR-212-5p. The luciferase assay indicated that miR-212-5p directly binds the conserved sequence GCCAA located in the 3'UTR of FAS and SCD1 to suppress the activity of FAS $3^{\prime}$ UTR or SCD1 3'UTR. Though miR-212-5p significantly inhibits the protein levels of FAS and SCD1, the mRNA levels of Fas and Scd1 cannot be influenced, which suggested that miR-212-5p regulates the expression of FAS and SCD1 on the translational level.

$D N L$ is critical for lipid accumulation in the liver (Postic \& Girard 2008). Given that miR-212-5p significantly suppressed the expression of FAS and SCD1, the effect of miR-212-5p on lipid accumulation in mouse primary hepatocytes and in the liver was determined. As expected, overexpression of miR-212-5p significantly inhibited the lipid accumulation in vitro and in vivo. Moreover, we found that miR-212-5p inhibitor can reverse the suppressive effect of leucine deprivation on the expression of FAS and SCD1, as well as lipid accumulation in mouse primary hepatocytes. These results indicated that miR-212-5p plays a key role in leucine deprivation-suppressed $D N L$. Based on the finding that miR-212 specifically suppressed the mRNA levels of Fas and Scd1 and increased the mRNA level of Cd36, we speculated that miR-212 suppressed lipid accumulation mainly due to the suppressed DNL. Otherwise, miR-212-5p could not influence the mRNA levels of $F a s$ and $S c d 1$ in mouse primary hepatocytes, which is different to the effect of miR-212 in mice. We surmised that two reasons might be responsible to this difference. One is the potential function of Ad-miR-212 which also expresses the isoform of miR-212-3p, besides of miR-212-5p. The other reason is the possible result of Ad-miR-212 acting on the complex environment in vivo. It is worth noting that miR-212 decreased the protein levels of FAS and SCD1 both in vitro and in vivo.

Previous work indicated that insulin (Shukla et al. 2013) and ethanol (Tang et al. 2008) induces the expression of miR-212. Our work suggests that leucine deprivation also induces the expression of miR-212. These results implied that miR-212 might be regulated by nutrition states, which need further investigation in the future. The GCN2/ATF4 pathway is critical for cell survival in response to leucine deprivation (Ye et al. 2010, Wang et al. 2013). Our study showed that leucine deprivation stimulated the GCN2/ATF4 pathway, and blocking the GCN2/ATF4 pathway via shGCN2 or siATF4 can reverse the higher expression of miR-212-5p induced by leucine deprivation in mouse primary hepatocytes. These results suggest that GCN2/ATF4 pathway mediates the expression of miR-212 induced

Published by Bioscientifica Ltd. 
by leucine deficiency, although the mechanisms need further investigation. It has been reported that FAS expression in liver is not suppressed by leucinedeficient diet in GCN2 knockout mice; as a sensor of amino acid deficiency, GCN2 was reported to involved in lipid metabolism via regulating genes related to the synthesis of fatty acids such as SREBP1c and its target FAS (Guo \& Cavener 2007). In our current study, we found that GCN2 mediates the inhibition of FAS expression by miR-212. Consistently, previous studies have suggested that GCN2 may have a relationship with body TG levels. It is shown that the GCN2/mTOR/S6K1 and AMPK pathways play important roles in regulating hepatic insulin sensitivity by leucine deprivation (Xiao et al. 2011); many studies have demonstrated that insulin resistance is accompanied by liver steatosis (Savage et al. 2007, Kumashiro et al. 2011, Birkenfeld \& Shulman 2014), which suggests that GCN2 may be involved in regulating hepatic TG levels. On the other hand, GCN2 may regulate other transcription factors like C/EBP $\beta$ and LXR $\alpha$ (Guo \& Cavener 2007), which may be involved in regulating fatty liver (Rahman et al. 2007, Schroeder-Gloeckler et al. 2007, Hijmans et al. 2015, Hsieh et al. 2016).

In this study, we also explored the possible role of miR-212 in regulating lipid metabolism following treatment with a HFD and found that miR-212 significantly ameliorated liver steatosis of mice induced by HFD. Various strategies have been proposed to treat NAFLD, including lifestyle modifications and pharmacologic interventions (Suzuki et al. 2005, Musso et al. 2010); however, our work suggests that miR-212 was involved in the regulation of nutrient-induced fatty liver, which may provide potential therapeutic approaches to NAFLD.

In summary, our study showed that leucine deprivation induces the expression of miR-212-5p in a GCN2/ATF4-dependent manner. miR-212-5p suppresses lipid accumulation in liver by targeting FAS and SCD1 under both normal diet and high-fat diet conditions. These findings proved a novel function of miR-212-5p in sensing leucine deprivation and regulating lipid metabolism in the livers of mice, which suggested that nutritional or pharmacological modulation of miR-212-5p-FAS/SCD1 axis could be potential therapeutic approaches for treating NAFLD.

\section{Supplementary data}

This is linked to the online version of the paper at http://dx.doi.org/10.1530/ JME-16-0179.
Declaration of interest

The authors declare that there is no conflict of interest that could be perceived as prejudicing the impartiality of the research reported.

\section{Funding}

This work was supported by grants from the National Natural Science Foundation (81130076, 81325005, 31271269, 81100615, 81390350 and 81471076), the Ministry of Science and Technology of China (973 Program 2010CB912502), Basic Research Project of Shanghai Science and Technology Commission (13JC1409000) and International S\&T Cooperation Program of China (Singapore 2014DFG32470). C Wang was supported by the Knowledge Innovation Program of Shanghai Institutes for Biological Sciences, the Chinese Academy of Sciences (2011KIP307) and the SA-SIBS Scholarship Program. F Guo was supported by the One Hundred Talents Program of the Chinese Academy of Sciences.

\section{Author contribution statement}

$Y$ Guo and $C$ Wang researched data and wrote, reviewed and edited the manuscript. J Yu, K Li, B Liu, Y Du, F Xiao and S Chen provided research material. F Guo directed the project, contributed to discussion, and wrote, reviewed, and edited the manuscript.

\section{References}

Ambros V 2001 microRNAs: tiny regulators with great potential. Cell 107 823-826. (doi:10.1016/S0092-8674(01)00616-X)

Averous J, Lambert-Langlais S, Cherasse Y, Carraro V, Parry L, B'Chir W, Jousse C, Maurin AC, Bruhat A \& Fafournoux P 2011 Amino acid deprivation regulates the stress-inducible gene $\mathrm{p} 8$ via the GCN2/ ATF4 pathway. Biochemical and Biophysical Research Communications 413 24-29. (doi:10.1016/j.bbrc.2011.08.028)

Bartel DP 2004 MicroRNAs: genomics, biogenesis, mechanism, and function. Cell 116 281-297. (doi:10.1016/S0092-8674(04)00045-5)

Betel D, Wilson M, Gabow A, Marks DS \& Sander C 2008 The microRNA.org resource: targets and expression. Nucleic Acids Research 36 D149-D153. (doi:10.1093/nar/gkm995)

Birkenfeld AL \& Shulman GI 2014 Nonalcoholic fatty liver disease, hepatic insulin resistance, and type 2 diabetes. Hepatology $\mathbf{5 9}$ 713-723. (doi:10.1002/hep.26672)

Bradbury MW 2006 Lipid metabolism and liver inflammation. I. Hepatic fatty acid uptake: possible role in steatosis. American Journal of Physiology: Gastrointestinal and Liver Physiology 290 G194-G198. (doi:10.1152/ajpgi.00413.2005)

Dai J, Wu H, Zhang Y, Gao K, Hu G, Guo Y, Lin C \& Li X 2016 Negative feedback between TAp63 and Mir-133b mediates colorectal cancer suppression. Oncotarget 7 87147-87160. (doi:10.18632/oncotarget.13515)

de Alwis NM \& Day CP 2008 Non-alcoholic fatty liver disease: the mist gradually clears. Journal of Hepatology $\mathbf{4 8}$ (Supplement 1) S104-S112. (doi:10.1016/j.jhep.2008.01.009)

Donnelly KL, Smith CI, Schwarzenberg SJ, Jessurun J, Boldt MD \& Parks EJ 2005 Sources of fatty acids stored in liver and secreted via lipoproteins in patients with nonalcoholic fatty liver disease. Journal of Clinical Investigation 115 1343-1351. (doi:10.1172/JCI23621)

Ducheix S, Lobaccaro JM, Martin PG \& Guillou H 2011 Liver X receptor: an oxysterol sensor and a major player in the control of lipogenesis. Chemistry and Physics of Lipids 164 500-514. (doi:10.1016/j. chemphyslip.2011.06.004)

Fabbrini E, Sullivan S \& Klein S 2010 Obesity and nonalcoholic fatty liver disease: biochemical, metabolic, and clinical implications. Hepatology 51 679-689. (doi:10.1002/hep.23280) 
Feng YY, Xu XQ, Ji CB, Shi CM, Guo XR \& Fu JF 2014 Aberrant hepatic microRNA expression in nonalcoholic fatty liver disease. Cellular Physiology and Biochemistry 34 1983-1997. (doi:10.1159/000366394)

Ferre P \& Foufelle F 2010 Hepatic steatosis: a role for de novo lipogenesis and the transcription factor SREBP-1c. Diabetes, Obesity and Metabolism 12 (Supplement 2) 83-92. (doi:10.1111/j.1463-1326.2010.01275.x)

Folch J, Lees M \& Sloane Stanley GH 1957 A simple method for the isolation and purification of total lipides from animal tissues. Journal of Biological Chemistry 226 497-509.

Guo F \& Cavener DR 2007 The GCN2 eIF2alpha kinase regulates fattyacid homeostasis in the liver during deprivation of an essential amino acid. Cell Metabolism 5 103-114. (doi:10.1016/j.cmet.2007.01.001)

Hanse EA, Mashek DG, Becker JR, Solmonson AD, Mullany LK, Mashek MT, Towle HC, Chau AT \& Albrecht JH 2012 Cyclin D1 inhibits hepatic lipogenesis via repression of carbohydrate response element binding protein and hepatocyte nuclear factor 4alpha. Cell Cycle $\mathbf{1 1}$ 2681-2690. (doi:10.4161/cc.21019)

He L \& Hannon GJ 2004 MicroRNAs: small RNAs with a big role in gene regulation. Nature Reviews Genetics 5 522-531. (doi:10.1038/nrg1379)

Hijmans BS, Tiemann CA, Grefhorst A, Boesjes M, van Dijk TH, Tietge UJ, Kuipers F, van Riel NA, Groen AK \& Oosterveer MH 2015 A systems biology approach reveals the physiological origin of hepatic steatosis induced by liver X receptor activation. FASEB Journal 29 1153-1164. (doi:10.1096/fj.14-254656)

Hinnebusch AG 1994 The eIF-2 alpha kinases: regulators of protein synthesis in starvation and stress. Seminars in Cell Biology $\mathbf{5}$ 417-426. (doi:10.1006/scel.1994.1049)

Hoekstra M, van der Sluis RJ, Kuiper J \& Van Berkel TJ 2012 Nonalcoholic fatty liver disease is associated with an altered hepatocyte microRNA profile in LDL receptor knockout mice. Journal of Nutritional Biochemistry 23 622-628. (doi:10.1016/j. jnutbio.2011.03.005)

Hsieh J, Koseki M, Molusky MM, Yakushiji E, Ichi I, Westerterp M, Iqbal J, Chan RB, Abramowicz S, Tascau L, et al. 2016 TTC39B deficiency stabilizes LXR reducing both atherosclerosis and steatohepatitis. Nature 535 303-307. (doi:10.1038/nature18628)

Iizuka K \& Horikawa Y 2008 ChREBP: a glucose-activated transcription factor involved in the development of metabolic syndrome. Endocrine Journal 55 617-624. (doi:10.1507/endocrj.K07E-110)

Incoronato M, Urso L, Portela A, Laukkanen MO, Soini Y, Quintavalle C, Keller S, Esteller M \& Condorelli G 2011 Epigenetic regulation of miR-212 expression in lung cancer. PLOS ONE 6 e27722. (doi:10.1371/journal.pone.0027722)

Jensen-Urstad AP \& Semenkovich CF 2012 Fatty acid synthase and liver triglyceride metabolism: housekeeper or messenger? Biochimica et Biophysica Acta 1821 747-753. (doi:10.1016/j.bbalip.2011.09.017)

Jiang X, Chen X, Chen L, Ma Y, Zhou L, Qi Q, Liu Y, Zhang S, Luo J \& Zhou X 2014 Upregulation of the miR-212/132 cluster suppresses proliferation of human lung cancer cells. Oncology Reports 33 705-712. (doi:10.3892/or.2014.3637)

Jin X, Ye YF, Chen SH, Yu CH, Liu J \& Li YM 2009 MicroRNA expression pattern in different stages of nonalcoholic fatty liver disease. Digestive and Liver Disease 41 289-297. (doi:10.1016/j. dld.2008.08.008)

Kersten S, Seydoux J, Peters JM, Gonzalez FJ, Desvergne B \& Wahli W 1999 Peroxisome proliferator-activated receptor alpha mediates the adaptive response to fasting. Journal of Clinical Investigation $\mathbf{1 0 3}$ 1489-1498. (doi:10.1172/JCI6223)

Kumashiro N, Erion DM, Zhang D, Kahn M, Beddow SA, Chu X, Still CD, Gerhard GS, Han X, Dziura J, et al. 2011 Cellular mechanism of insulin resistance in nonalcoholic fatty liver disease. PNAS $\mathbf{1 0 8}$ 16381-16385. (doi:10.1073/pnas.1113359108)

Lawes J \& Gilbert J 1877 On the formation of fat in the animal body. Journal of Anatomy and Physiology 11 577-588.1. (doi:10.1039/ MP8410100164)
Leone TC, Weinheimer CJ \& Kelly DP 1999 A critical role for the peroxisome proliferator-activated receptor alpha (PPARalpha) in the cellular fasting response: the PPARalpha-null mouse as a model of fatty acid oxidation disorders. PNAS 96 7473-7478. (doi:10.1073/ pnas.96.13.7473)

Liang X, Zeng J, Wang L, Fang M, Wang Q, Zhao M, Xu X, Liu Z, Li W, Liu S, et al. 2013 Histone demethylase retinoblastoma binding protein 2 is overexpressed in hepatocellular carcinoma and negatively regulated by hsa-miR-212. PLOS ONE $\mathbf{8}$ e69784. (doi:10.1371/journal.pone.0069784)

Ma C, Nong K, Wu B, Dong B, Bai Y, Zhu H, Wang W, Huang X, Yuan Z \& Ai K 2014 miR-212 promotes pancreatic cancer cell growth and invasion by targeting the hedgehog signaling pathway receptor patched-1. Journal of Experimental and Clinical Cancer Research 3354. (doi:10.1186/1756-9966-33-54)

Miyaaki H, Ichikawa T, Kamo Y, Taura N, Honda T, Shibata H, Milazzo M, Fornari F, Gramantieri L, Bolondi L, et al. 2014 Significance of serum and hepatic microRNA-122 levels in patients with non-alcoholic fatty liver disease. Liver International $\mathbf{3 4}$ e302-e307. (doi:10.1111/liv.12429)

Musso G, Gambino R, Cassader M \& Pagano G 2010 A meta-analysis of randomized trials for the treatment of nonalcoholic fatty liver disease. Hepatology 52 79-104. (doi:10.1002/hep.23623)

Ntambi JM 1992 Dietary regulation of stearoyl-CoA desaturase 1 gene expression in mouse liver. Journal of Biological Chemistry 267 10925-10930.

Pirola CJ, Gianotti TF, Castano GO \& Sookoian S 2013 Circulating MicroRNA-122 signature in nonalcoholic fatty liver disease and cardiovascular disease: a new endocrine system in metabolic syndrome. Hepatology 57 2545-2547. (doi:10.1002/hep.26116)

Pirola CJ, Fernandez Gianotti T, Castano GO, Mallardi P, San Martino J, Mora Gonzalez Lopez Ledesma M, Flichman D, Mirshahi F, Sanyal AJ \& Sookoian S 2015 Circulating microRNA signature in non-alcoholic fatty liver disease: from serum non-coding RNAs to liver histology and disease pathogenesis. Gut 64 800-812. (doi:10.1136/ gutjnl-2014-306996)

Postic C \& Girard J 2008 Contribution of de novo fatty acid synthesis to hepatic steatosis and insulin resistance: lessons from genetically engineered mice. Journal of Clinical Investigation 118 829-838. (doi:10.1172/JCI34275)

Rahman SM, Schroeder-Gloeckler JM, Janssen RC, Jiang H, Qadri I, Maclean KN \& Friedman JE 2007 CCAAT/enhancing binding protein beta deletion in mice attenuates inflammation, endoplasmic reticulum stress, and lipid accumulation in diet-induced nonalcoholic steatohepatitis. Hepatology 45 1108-1117. (doi:10.1002/ hep.21614)

Samuel VT \& Shulman GI 2012 Mechanisms for insulin resistance: common threads and missing links. Cell 148 852-871. (doi:10.1016/j.cell.2012.02.017)

Samuel VT, Petersen KF \& Shulman GI 2010 Lipid-induced insulin resistance: unravelling the mechanism. Lancet 375 2267-2277. (doi:10.1016/S0140-6736(10)60408-4)

Savage DB, Petersen KF \& Shulman GI 2007 Disordered lipid metabolism and the pathogenesis of insulin resistance. Physiological Reviews $\mathbf{8 7}$ 507-520. (doi:10.1152/physrev.00024.2006)

Schroeder-Gloeckler JM, Rahman SM, Janssen RC, Qiao L, Shao J, Roper M, Fischer SJ, Lowe E, Orlicky DJ, McManaman JL, et al. 2007 CCAAT/enhancer-binding protein beta deletion reduces adiposity, hepatic steatosis, and diabetes in Lepr(db/db) mice. Journal of Biological Chemistry 282 15717-15729. (doi:10.1074/jbc. M701329200)

Shukla U, Tumma N, Gratsch T, Dombkowski A \& Novak RF 2013 Insights into insulin-mediated regulation of CYP2E1: miR-132/-212 targeting of CYP2E1 and role of phosphatidylinositol 3-kinase, Akt (protein kinase B), mammalian target of rapamycin signaling in regulating miR-132/-212 and miR-122/-181a expression in primary

Published by Bioscientifica Ltd. 
cultured rat hepatocytes. Drug Metabolism and Disposition 41 1769-1777. (doi:10.1124/dmd.113.052860)

Soh J, Iqbal J, Queiroz J, Fernandez-Hernando C \& Hussain MM 2013 MicroRNA-30c reduces hyperlipidemia and atherosclerosis in mice by decreasing lipid synthesis and lipoprotein secretion. Nature Medicine 19 892-900. (doi:10.1038/nm.3200)

Strable MS \& Ntambi JM 2010 Genetic control of de novo lipogenesis: role in diet-induced obesity. Critical Reviews in Biochemistry and Molecular Biology 45 199-214. (doi:10.3109/10409231003667500)

Suzuki A, Lindor K, St Saver J, Lymp J, Mendes F, Muto A, Okada T \& Angulo P 2005 Effect of changes on body weight and lifestyle in nonalcoholic fatty liver disease. Journal of Hepatology $\mathbf{4 3}$ 1060-1066. (doi:10.1016/j.jhep.2005.06.008)

Tang Y, Banan A, Forsyth CB, Fields JZ, Lau CK, Zhang LJ \& Keshavarzian A 2008 Effect of alcohol on miR-212 expression in intestinal epithelial cells and its potential role in alcoholic liver disease. Alcoholism Clinical and Experimental Research 32 355-364. (doi:10.1111/j.1530-0277.2007.00584.x)

Ucar A, Vafaizadeh V, Jarry H, Fiedler J, Klemmt PA, Thum T, Groner B \& Chowdhury K 2010 miR-212 and miR-132 are required for epithelial stromal interactions necessary for mouse mammary gland development. Nature Genetics 42 1101-1108. (doi:10.1038/ng.709)

Wang Q, Jiang L, Wang J, Li S, Yu Y, You J, Zeng R, Gao X, Rui L, Li W, et al. 2009 Abrogation of hepatic ATP-citrate lyase protects against fatty liver and ameliorates hyperglycemia in leptin receptor-deficient mice. Hepatology 49 1166-1175. (doi:10.1002/hep.22774)
Wang Y, Ning Y, Alam GN, Jankowski BM, Dong Z, Nor JE \& Polverini PJ 2013 Amino acid deprivation promotes tumor angiogenesis through the GCN2/ATF4 pathway. Neoplasia 15 989-997. (doi:10.1593/neo.13262)

Wang XC, Zhan XR, Li XY, Yu JJ \& Liu XM 2014 MicroRNA-185 regulates expression of lipid metabolism genes and improves insulin sensitivity in mice with non-alcoholic fatty liver disease. World Journal of Gastroenterology 20 17914-17923. (doi:10.3748/wjg.v20.i47.17914)

Wei LQ, Liang HT, Oin DC, Jin HF, Zhao Y \& She MC 2014 MiR-212 exerts suppressive effect on SKOV3 ovarian cancer cells through targeting HBEGF. Tumor Biology 35 12427-12434. (doi:10.1007/ s13277-014-2560-2)

Wilfred BR, Wang WX \& Nelson PT 2007 Energizing miRNA research: a review of the role of miRNAs in lipid metabolism, with a prediction that miR-103/107 regulates human metabolic pathways. Molecular Genetics and Metabolism 91 209-217. (doi:10.1016/j. ymgme.2007.03.011)

Xiao F, Huang Z, Li H, Yu J, Wang C, Chen S, Meng Q, Cheng Y, Gao X, $\mathrm{Li}$ J, et al. 2011 Leucine deprivation increases hepatic insulin sensitivity via GCN2/mTOR/S6K1 and AMPK pathways. Diabetes 60 746-756. (doi:10.2337/db10-1246)

Ye J, Kumanova M, Hart LS, Sloane K, Zhang H, De Panis DN, Bobrovnikova-Marjon E, Diehl JA, Ron D \& Koumenis C 2010 The GCN2-ATF4 pathway is critical for tumour cell survival and proliferation in response to nutrient deprivation. EMBO Journal 29 2082-2096. (doi:10.1038/emboj.2010.81)

Received in final form 4 June 2017

Accepted 29 June 2017

Accepted Preprint published online 30 June 2017
() 2017 Society for Endocrinology Printed in Great Britain
Published by Bioscientifica Ltd 